\title{
ESTUDO COMPARATIVO DA POLINIZAÇÃO DE Mangifera indica L. EM CULTIVO CONVENCIONAL E ORGÂNICO NA REGIÃO DO VALE DO SUBMÉDIO DO SÃO FRANCISCO ${ }^{1}$
}

\author{
KÁTIA MARIA MEDEIROS DE SIQUEIRA ${ }^{2}$, LÚCIA HELENA PIEDADE KIILL ${ }^{3}$, CELSO FEITOSA MARTINS ${ }^{4}$, \\ IVANICE BORGES LEMOS ${ }^{5}$, SABRINA PITOMBEIRAMONTEIRO ${ }^{5}$, EDSÂNGELA DE ARAÚJO FEITOZA ${ }^{5}$
}

RESUMO-O presente estudo foi desenvolvido durante os anos de 2005/2006, em plantio comercial de mangueira, da variedade Tommy Atkins, na Fazenda Frutex, em Petrolina-PE, objetivando verificar a biologia floral, bem como o estudo comparativo sobre o comportamento, a freqüência e a sazonalidade dos visitantes florais em cultivo orgânico e convencional. As inflorescências da mangueira apresentam flores masculinas e hermafroditas, na proporção de 2:1, com predominância das primeiras na base da panícula. A antese é diurna, assincrônica, com liberação de forte odor adocicado. As flores apresentam dicogamia, caracterizada pela deiscência das anteras $24 \mathrm{~h}$ após a antese. A produção de néctar é contínua e em pequenas quantidades, em média $0,045 \mu \mathrm{L}$ por flor. Quanto aos visitantes florais foram registradas 21 espécies, pertencentes às ordens: Diptera, Hymenoptera, Lepidoptera e Odonata. Apis mellifera foi a espécie mais freqüente nos dois tipos de cultivo. Dentre os dípteros, destacaram-se Belvosia bicincta (17,7\%) e Musca domestica $(10,2 \%)$ como as mais freqüentes em cultivo convencional e orgânico, respectivamente. A diversidade e o número de visitas foram maiores em cultivo orgânico. A utilização de agrotóxicos durante a floração reduziu a freqüência de visitas das abelhas em $50 \%$ e dos dípteros em 20\%. Devido ao seu comportamento, freqüência e ativo deslocamento nas inflorescências, A. mellifera foi considerada como o polinizador mais eficiente da cultura para a região do Vale do Submédio São Francisco.

Termos para indexação: dípteros, Musca domestica, Apis mellifera, Belvosia bicincta, mangueira.

\section{COMPARATIVE STUDY OF POLLINATION OF Mangifera indica L. IN CONVENTIONAL AND ORGANIC CROPS IN THE REGION OF THE SUBMÉDIO SÃO FRANCISCO VALLEY}

\begin{abstract}
This study was carried out in 2005 and 2006, in a commercial mango Tommy Atkins plantation on Frutex Farm, in Petrolina-PE. The objective was to verify the floral biology as well as the comparative study of behaviour, the frequency and the seasonality of the floral visitors in both organic and conventional crops. The mango tree inflorescences present male and hermaphrodite flowers $(2: 1)$, with predominance of the first ones in the basis of the panicles. The anthesis is diurnal, asynchronic, with liberation of strong and sweat odour. The flowers present dicogamy, characterized by the anthers dehiscence 24 hours after the anthesis. The nectar production is continuous and in small amounts, on an average of $0,045 \mu \mathrm{L} /$ flower. Concerning the flower visitors, 21 species were registered, belonging to the orders Diptera, Hymenoptera, Lepidoptera and Odonata. Apis mellifera was the most frequent visitant in both types of crops. Among the Diptera, Belvosia bicincta $(17,7 \%)$ and Musca domestica $(10,2 \%)$ were the most frequent visitors in conventional and organic crops, respectively. The diversity and number of visitors were higher in the organic crop. The use of agrotoxics during the flowering period reduced the visit of bees (50\%) and Diptera $(20 \%)$. Because of its behaviour, frequency and active movement in the inflorescences, Apis mellifera was considered as the most efficient pollinator of the crop for the region of the São Francisco Submédio Valley.
\end{abstract}

Index Terms: diptera, Musca domestica, Apis mellifera, Belvosia bicincta,mango.

\section{INTRODUÇÃO}

A mangicultura na região do Vale do Submédio São Francisco destaca-se, em nível nacional e internacional, não apenas pela qualidade dos frutos produzidos, mas também pelo desenvolvimento de tecnologias específicas no manejo da floração, associadas às condições climáticas, possibilitando assim uma produção escalonada durante todo o ano. $\mathrm{O}$ escalonamento da produção é obtido por meio da utilização de reguladores vegetais, prática que permite o atendimento racional da demanda, considerando-se épocas mais favoráveis do ponto de vista comercial. Assim, na cultura da mangueira é possível acompanhar duas floradas no ano, uma na estação seca (maio a outubro) e outra na estação chuvosa (novembro a abril). Apesar da intensa florada, a quantidade de frutos que vingam e amadurecem é pequena.

Estudos relativos à biologia floral e importância da polinização para a produção de frutos na mangueira (Mangifera indica L.) foram desenvolvidos a partir do início do século XX,

'(Trabalho 146-07). Recebido em: 06-06-2007. Aceito para publicação em; 29-02-2008. Parte da tese da primeira autora no curso de Pós-graduação em Ciências Biológicas (Zoologia), CCEN, UFPB, João Pessoa-PB e do projeto Diagnóstico de polinizadores no Vale do São Francisco.

${ }^{2}$ Ms. em Biol. Animal, Universidade do Estado da Bahia, Campus III, Juazeiro-BA, Cefet-Petrolina, katiauneb@bol.com.br

${ }^{3}$ Dra. em Biol. Vegetal, pesquisadora Embrapa Semi-Árido, kiill@cpatsa.embrapa.br

${ }^{4}$ Dr. em Zooogia, Departamento de Sistemática e Ecologia, Universidade Federal da Paraíba, cmartins@dse.ufpb.br.

${ }^{5}$ Bolsista Apoio Técnico - AT/CNPq, Embrapa Semi-Árido. 
porém existem pontos de vista variados entre os autores quanto à estratégia reprodutiva (Young, 1942; Sturrock 1944; Singh et al., 1962; MacGregor, 1976; Singh 1989, 1997). Dag \& Gazit (2000), em experimentos realizados em Israel, com a variedade Keitt, em plantas de pequeno porte, obtiveram produção de $1 \mathrm{~kg} /$ planta, quando as flores não recebiam visitação e $61 \mathrm{~kg} / \mathrm{planta} \mathrm{em}$ polinização aberta. Neste mesmo experimento, foram registradas 46 espécies diferentes de insetos, pertencentes às ordens Diptera, Hymenoptera e Coleoptera, sendo considerados pelos autores como polinizadores efetivos, os dípteros e abelhas melíferas (Apis mellifera). Singh (1997) observou que panículas completamente ensacadas não desenvolviam frutos e que, quanto maior o tempo de exposição da panícula à visitação, maior o número de frutos produzidos. Por outro lado, Young (1942), em experimentos na Flórida com a variedade Haden, não encontrou diferença significativa na produção de frutos oriundos da autopolinização e da polinização cruzada.

As informações sobre a ação dos visitantes florais nas inflorescências da mangueira, principalmente aquelas relacionadas à polinização, ainda necessitam de estudos complementares, uma vez que as conseqüências desta atividade, além de estarem diretamente ligadas à morfologia, biologia floral e sistema reprodutivo da planta, encontram-se dependentes também do manejo da cultura, das condições climáticas e da vegetação do seu entorno, além do comportamento de forrageamento dos polinizadores.

O pólo de produção de manga no Submédio do Vale do São Francisco está localizado na região semi-árida, no ecossistema Caatinga, o qual apresenta fauna e flora diferenciadas, necessitando de conhecimentos que integrem e racionalizem o uso da agricultura regional com o seu entorno. Com o objetivo de estudar esses aspectos, foram desenvolvidos experimentos na cultura da mangueira, variedade Tommy Atkins, em área de cultivo convencional e orgânico, em Petrolina-PE, nos anos de 2005 e 2006

\section{MATERIAL E MÉTODOS}

Este trabalho foi desenvolvido na Fazenda Frutex, município de Petrolina-PE ( $09^{\circ} 09^{\prime} \mathrm{S}, 40^{\circ} 22^{\prime} \mathrm{W}$, com $376 \mathrm{~m}$ de altitude), durante os anos de 2005 e 2006. O clima da região é semi-árido, a precipitação pluviométrica média anual é de $435 \mathrm{~mm}$, com as chuvas concentradas no período de novembro a abril (Figura 1).

Os experimentos foram desenvolvidos com a variedade Tommy Atkins em cultivo convencional e orgânico, com áreas de 200 ha e 5 ha, respectivamente, e com espaçamento de $5 \mathrm{~m} \mathrm{x}$ $10 \mathrm{~m}$, localizadas na mesma propriedade e distantes cerca de $3 \mathrm{~km}$. As plantas apresentavam a mesma idade (13 anos), porém, no segundo caso, o cultivo vem sendo manejado de forma orgânica nos últimos três anos. O sistema de irrigação utilizado no campo, nas duas áreas, é do tipo microaspersão.

Para os estudos de morfologia floral, foram marcadas aleatoriamente 60 panículas, em 10 plantas, localizadas em duas linhas centrais da parcela em floração. Para as observações da biologia floral (horário, coloração, duração e seqüência da antese), 17 panículas foram marcadas em oito indivíduos escolhidos ao acaso e acompanhadas diariamente. Para determinar os diferentes tipos florais com relação à posição na inflorescência e proporção de flores hermafroditas e masculinas, foram avaliadas cinco panículas de cada tipo de cultivo, coletadas aleatoriamente, na área experimental. Observações complementares foram feitas por meio de registro fotográfico, bem como em flores fixadas em álcool a $70 \%$, analisadas sob microscópio estereoscópico, no Laboratório de Biotecnologia, da Embrapa Semi-Árido.

Para estimar a viabilidade dos grãos de pólen, anteras, logo após a deiscência $(n=10)$, foram utilizadas na preparação de lâminas, seguindo a técnica de coloração de Radford et al. (1974). $\mathrm{O}$ número de grãos por anteras $(\mathrm{n}=10)$ foi obtido, a partir de botões em pré-antese, fixados em álcool a $70 \%$. O cálculo da razão pólen/óvulo foi realizado segundo Cruden (1977). O volume de néctar, coletado em 50 flores, foi obtido a partir de coletas realizadas entre $8 \mathrm{~h}$ e $16 \mathrm{~h}$, utilizando-se da técnica do ponto, segundo Kearns e Inouye (1993).

Os visitantes florais foram observados durante todo o período de floração, em dias alternados, no período matutino $(7 \mathrm{~h}$ às $12 \mathrm{~h}$ ) e vespertino (12h01 às $18 \mathrm{~h})$, sendo anotadas a freqüência, a duração e o horário das visitas, o comportamento dos visitantes mais freqüentes, bem como o recurso floral forrageado. Para cada intervalo de observação (por ex: 6h-7h), foram feitas, no mínimo, cinco repetições. As visitas observadas foram somadas e, posteriormente, divididas pelo número de repetições, para calcular o número médio de visitas de cada intervalo. O esforço amostral das observações foi de 272 horas.

De acordo com o comportamento apresentado, os visitantes foram considerados como polinizadores (Dafni, 1992) ou pilhadores (Inouye, 1980). Quanto à freqüência, os visitantes foram classificados em: Abundantes (A), quando apresentavam freqüência de visitas $>30 \%$; Freqüentes $(\mathrm{F})$, quando apresentavam freqüência de visitas de $10 \%$ a $30 \%$, e Raros (R), quando apresentavam freqüências $<10 \%$. Alguns visitantes foram capturados, fixados e mantidos a seco, para posterior identificação e exame dos locais de deposição de pólen. Para análise mais detalhada do comportamento, foram tomadas fotografias e filmagens. Os visitantes coletados foram depositados no Laboratório de Ecologia da Embrapa Semi-Árido.

Para avaliar a interferência dos produtos químicos no comportamento dos visitantes florais, foram feitas observações nas áreas de cultivo convencional e orgânico, antes e após a pulverização. Estudos comparativos também foram feitos ao longo da floração com o objetivo de verificar a sazonalidade na visitação.

\section{RESULTADOS E DISCUSSÃO}

Na mangueira da variedade Tommy Atkins, as flores são simples, rasas, de cores claras, com guias de néctar, exalam odor adocicado e estão reunidas em inflorescências terminais do tipo panícula, ramificada, de forma piramidal, com a raque comumente ereta, apresentando coloração avermelhada, que auxilia no processo de atração visual dos insetos. 
Quanto ao número de flores por panícula, verificou-se que as inflorescências apresentam números variados, sendo encontrados, em média, 968,7 botões por inflorescência e 471,8 flores abertas por dia. A análise morfológica das inflorescências mostrou que as panículas no cultivo convencional apresentam maior número de flores e botões do que no cultivo orgânico (Tabela 1), o que pode estar relacionado com o método de indução floral do cultivo, que, no primeiro caso, é feito com a aplicação de paclobutrazol (PBZ) e, no segundo, com urina de vaca. A média registrada concorda com os dados de literatura, sendo de 500 a 10.000 flores por panícula, cuja variação também está relacionada com a variedade da mangueira (Raghava Kurup, 1967).

Em relação aos tipos florais, as inflorescências da mangueira apresentam flores masculinas e hermafroditas, sendo que as primeiras apresentam gineceu rudimentar, quatro a cinco estaminódios, um estame com anteras monotecas, e o nectário apresenta-se na forma de um disco, no centro da flor. Já as flores hermafroditas apresentam ovário súpero, uniovulado, estilete e estigma simples. $\mathrm{O}$ androceu apresenta composição semelhante ao descrito para as flores masculinas. O nectário apresenta- se na forma de um disco hipógino.

As análises das panículas quanto ao tipo floral revelaram em ambos os cultivos que cerca de $70 \%$ são de flores masculinas, o que equivale à proporção de $2: 1$, concordando com a variação apresentada por Ochse et al. (1961) e por Fraser (1927). Quanto à distribuição dos tipos florais, na inflorescência, observou-se predominância de flores masculinas na base e no meio das inflorescências nos dois sistemas de cultivo (Tabela 1).

Os grãos de pólen de botões florais em pré-antese apresentaram 93\% de viabilidade. Os estames apresentaram 920 grãos por antera em média, apresentando forma esférica e o tamanho variando de 16,04 a $28,5 \mu \mathrm{m}$. Dentre os estaminóides analisados nos dois tipos florais, somente em uma flor hermafrodita foi registrada produção de pequena quantidade de grãos, cerca de $1 \%$ do encontrado para os estames. Assim, com base nos dados obtidos, a razão pólen/óvulo foi de 920, indicando que o sistema reprodutivo dessa espécie pode ser considerado como facultativamente xenogâmico, de acordo com Cruden (1977).

A antese das flores é diurna, porém assincrônica, sendo registradas flores abrindo ao longo de todo o dia. As flores recémabertas apresentam corola de cor creme, anteras de cor violeta (Figura 2a) e o estigma encontra-se receptivo. Nesta fase, um odor forte e adocicado é exalado pelas flores, funcionando como atrativo a longa distância.

A corola permanece sem modificações por, aproximadamente, 24 horas, quando então se verifica o início da mudança de coloração das pétalas, com o aparecimento de tons rosados nas extremidades distais (Figura 2b). As anteras passam a apresentar coloração preta e, nesta fase, ocorre a deiscência, com o início da desidratação das tecas e exposição dos grãos de pólen, de coloração esbranquiçada. Após 48 horas do início da antese, as pétalas adquirem tons avermelhados, com guias de néctar de coloração marrom. Nesta fase, verificou-se alteração de cor dos filetes dos estames e dos estaminóides, que passam a ter coloração vinácea, o que caracteriza o início da senescência floral. Assim, embora as flores sejam hermafroditas, nas primeiras 24 horas, somente o estigma está receptivo, sendo as mesmas funcionalmente femininas. Essa hercogamia favorece a polinização cruzada.

Quanto ao nectário, observou-se que sua produção é constante, porém com secreção de pequenas quantidades (em média $0,045 \mu \mathrm{L} /$ flor). No campo, era visível o acúmulo de néctar ao redor do ovário, deixando-o com aspecto viscoso e brilhante. Comparando-se o volume de néctar registrado em diferentes horários ao longo do dia, verificou-se que, no início da manhã, ocorreu acúmulo ligeiramente menor do que nos demais horários.

A abertura das flores em diferentes horários, associada à produção constante de néctar em pequenas quantidades, é vantajosa para a espécie, que assim mantém a oferta deste recurso de forma contínua, garantindo a visitação dos insetos ao longo do dia, bem como possibilitando que os mesmos visitem maior número de flores, garantindo, assim, a transferência de pólen entre flores e entre plantas. Além disso, essa disponibilidade de grande número de flores nas panículas confere, concomitantemente, atratividade visual e olfativa facilmente detectada a distância pelos visitantes florais que são fortemente atraídos para a cultura.

As flores da mangueira, em cultivo convencional e orgânico, foram visitadas por 21 espécies de insetos pertencentes às ordens: Diptera, Hymenoptera, Lepidoptera e Odonata. O néctar foi o recurso floral forrageado por todos os visitantes, com exceção de $A$. mellifera, que visitou as flores para coleta de néctar e pólen (Tabela 2). No cultivo orgânico, verificou-se que o número de espécies de himenópteros foi superior ao de cultivo convencional, sendo o inverso registrado em relação aos dípteros. Entre os visitantes, Apis mellifera (Hymenoptera, Apidae) foi a mais freqüente, sendo responsável por $68,3 \%$ do total de visitas em cultivo orgânico e $45,6 \%$ em cultivo convencional. Belvosia bicincta (Diptera, Tachinidae) foi a mais freqüente em cultivo convencional (17,7\%), enquanto a Musca domestica (Diptera, Muscidae) (10,27\%) foi a mais freqüente em cultivo orgânico. As visitas das demais espécies foram registradas com freqüências abaixo de $10 \%$, sendo, assim, consideradas raras. Dados semelhantes, relativos às ordens de insetos, foram citados por Singh (1989) e Jiron \& Hedstrom (1985), destacando maior freqüência de visitação para os dípteros. Em relação à $A$. mellifera, os autores comentam que suas visitas foram raras ou não foram observadas, discordando das observações feitas neste estudo. Porém, em estudo realizado no município de Juazeiro-BA, foram registradas freqüências de $67,5 \%$ para os dípteros e 17,5\% para os himenópteros (Viana et al., 2006). Essas diferenças podem ser relacionadas com a fauna disponível no entorno da cultura, sazonalidade dos visitantes e o próprio manejo da cultura. Neste estudo, a vegetação nativa no entorno do plantio, bem como a presença de manchas de vegetação próximas aos cultivos, servindo de abrigo natural para os insetos, principalmente para as colônias de Apis mellifera, pode ter sido um dos fatores responsáveis pela abundância desses insetos na área. Assim, vale salientar que o design da cultura é um fator importante para a manutenção dos polinizadores nas áreas cultivadas. 
Entre os himenópteros, A. mellifera apresentou dois tipos de comportamentos de visita, um para coleta de néctar e outro para coleta de pólen, sendo o visitante mais freqüente nos dois tipos de cultivo. Para a coleta de néctar, a abelha pousava diretamente sobre a flor, introduzia a glossa na região central da corola, tateando o nectário, em busca do néctar. Ao realizar este comportamento, a abelha tocava com a cabeça, pernas e parte ventral do corpo as estruturas reprodutivas, ficando o pólen aí depositado, o que caracteriza a polinização esternotríbica. Após coletar o néctar de uma flor, a abelha caminhava sobre a inflorescência, visitando outras flores abertas. As panículas localizadas na parte superior da copa e expostas ao sol mostraram maior preferência por parte dos visitantes.

Comportamento semelhante ao de coleta de néctar foi registrado para os demais himenópteros, porém não foi observado que os mesmos contatavam as estruturas reprodutivas durante as visitas por apresentarem porte inadequado ao tamanho da flor, podendo então ser considerados como pilhadores deste recurso floral.

Para a coleta de pólen, A. mellifera aproximava-se das flores, pousava sobre a corola e, com o auxílio das peças bucais e pernas, retirava o pólen das anteras. Posteriormente, a abelha transferia o recurso coletado para as corbículas. Além disso, foi observado durante a visita comportamento de limpeza do corpo, pernas e asas, armazenando o pólen nas corbículas. Ao final da coleta, as corbículas apresentavam-se repletas de pólen, com formato de esferas de cor acinzentada. Esse comportamento foi registrado somente no início da manhã. A análise do pólen retirado das corbículas $(\mathrm{n}=10)$ mostrou que os mesmos estavam impregnados com resina, apresentando consistência pegajosa, e a avaliação quantitativa indicou que $100 \%$ dos grãos eram de M. indica.

Quanto ao comportamento de visita, os dípteros alimentaram-se de néctar. Durante suas visitas, B. bicincta e $P$. vinetorum (Diptera, Syrphidae) pousavam sobre a flor, inseriam a probóscide na região central da flor, de onde coletavam o néctar. Ao realizar esse comportamento, os dípteros tocavam com a região ventral do corpo as estruturas reprodutivas, ficando o pólen aí depositado, caracterizando, assim, a polinização esternotríbica. Após a visita a uma flor, o inseto, geralmente, abandonava a panícula, visitando outras flores próximas ou, então, abandonava o local. Comportamento semelhante foi registrado para os demais dípteros; porém, em virtude do pequeno porte, esses insetos durante a visita não contatavam as estruturas reprodutivas das flores, sendo então considerados como pilhadores de néctar. Viana et al. (2006), levando em consideração a compatibilidade do tamanho do visitante com a morfologia floral, também consideraram os visitantes de pequeno porte menos eficientes como polinizadores da mangueira.

Durante as observações, registrou-se, ainda, comportamento agonístico dessas abelhas em relação aos demais insetos, principalmente quanto à Palpada vinetorum (Diptera, Syrphidae). Nesta situação, as operárias de A. mellifera impediam que os insetos se aproximassem das flores ou, uma vez pousadas na flor, as abelhas interferiam na visitação, afastando-as das panículas. Esse tipo de comportamento pode ter sido uma das causas da diferença de composição registrada entre os dois tipos de cultivos (Tabela 2).

Com relação ao tempo de permanência na inflorescência, houve diferença entre os dípteros mais freqüentes e $A$. mellifera. De modo geral, independentemente do tipo de cultivo, os dípteros passavam mais tempo na inflorescência do que as abelhas (Figura 3).

Ao se deslocar ativamente pela panícula, A. mellifera tem a possibilidade de contatar os dois tipos florais, favorecendo assim a polinização entre flores da inflorescência, entre panículas distintas e entre plantas, garantindo o fluxo de pólen na população. Ao longo das observações, foi freqüente a presença de vários indivíduos visitando uma mesma inflorescência, sendo observadas até 10 abelhas por panícula. Os dípteros, por demorarem mais tempo nas inflorescências e por apresentarem pouca atividade de deslocamento, visitam um número menor de flores e, como o número de flores masculinas é superior ao de hermafroditas, estes visitantes teriam menores possibilidades de contatar as flores femininas e, portanto, seriam menos eficientes no processo de polinização da mangueira.

Quanto à utilização de abelhas melíferas em cultivos de mangueiras, alguns autores constataram a eficiência e a facilidade de manejo das colméias em experimentos controlados como também em cultivos produtivos (Dag \& Gazit, 2000; Dag et al., 2001; Kiill \& Siqueira, 2006). Esses insetos vêm sendo utilizados, com sucesso, nos serviços de polinização de outras culturas de interesse econômico (D'Avila \& Marchine, 2005).

Lembrando que a floração da mangueira, na região do Vale do Submédio do São Francisco, ocorre de forma induzida e concentrada em períodos definidos do ano, o uso racional de polinizadores da ordem Díptera não seria recomendado no momento, pois ainda há pouca informação quanto ao seu ciclo biológico, reprodução e ecologia desses insetos. Além disso, as características descritas quanto ao comportamento indicam que, mesmo que haja disponibilidade de insetos na área, estes poderiam não oferecer uma polinização adequada. Por outro lado, para manter esses insetos na área, seria necessário ofertar substratos para nidificação, sendo que estes, na maioria dos casos, não estão de acordo com as recomendações da Produção Integrada de Frutas, o que inviabiliza a utilização dessa prática.

No cultivo convencional, ocorreu concentração das visitas no período da manhã, com redução progressiva à tarde. $\mathrm{O}$ pico de visitação foi registrado entre $8 \mathrm{~h} 30$ e $11 \mathrm{~h} 30$. Já no cultivo orgânico, foram registrados dois picos de visitação, um logo no início da manhã ( $7 \mathrm{~h} 30$ às $8 \mathrm{~h} 30)$ e outro no início da tarde ( $14 \mathrm{~h} 30$ às 15h30), observando-se um equilíbrio quantitativo em relação aos outros horários (Figura 4). Comparando-se os dados, notase que houve maior número de visitas no cultivo orgânico, sendo que essa diferença pode ser atribuída à ausência de aplicação de agroquímicos na área orgânica.

Quanto à freqüência de visita, A. mellifera esteve presente em praticamente todos os horários, com exceção do período de $9 \mathrm{~h} 30$ às $11 \mathrm{~h} 30$, no cultivo orgânico, e no último intervalo da tarde, no cultivo convencional (Figuras 5 a e $5 b$ ). Nesses períodos, houve aumento do número de espécies e da freqüência dos demais visitantes nos dois tipos de cultivo. No cultivo orgânico, 
essas abelhas apresentaram o dobro da média de visitas em relação ao cultivo convencional. Considerando esses dados e o comportamento descrito para as abelhas, pode-se inferir que há competição entre os visitantes e que o comportamento agonístico apresentado por $A$. mellifera estaria interferindo no padrão de visitação dos demais insetos.

No que diz respeito à visitação em cultivo convencional, durante a estação seca e a chuvosa (Figura 6), observou-se que A. mellifera esteve presente nas duas estações e em todos os intervalos de observações, tendo maior pico de visitação na estação chuvosa, no intervalo das $14 \mathrm{~h}$ às $15 \mathrm{~h}$. A presença de $A$. mellifera, ao longo do ano, revela que esta espécie está bem adaptada às condições climáticas da região, sendo encontrada com freqüência em áreas nativas no entorno da cultura. Por outro lado, Palpada vinetorum esteve presente apenas na estação chuvosa, com pico de visitação das $11 \mathrm{~h}$ às $12 \mathrm{~h}$, indicando que esses insetos necessitam de condições climáticas mais favoráveis.

No Brasil, informações sobre sírfideos como polinizadores foram registradas somente em áreas remanescentes de floresta em Pernambuco, no Vale do Rio Pardo, no Rio Grande do Sul, e em área de mata, em São Paulo, indicando a preferência desses insetos por ambientes mais úmidos (Arruda \& Sazima, 1996; Machado \& Loiola, 2000; Morales \& Köhler, 2006).

Quanto à influência da aplicação de agroquímicos na diversidade de visitantes, a avaliação mostrou que houve redução de $50 \%$ e de $20 \%$ na abundância de espécies de abelhas e moscas, respectivamente, após a pulverização de fungicidas e inseticidas (Figura 7). Comparando a visitação no período da manhã e da tarde após a aplicação, verificou-se que a maior redução foi registrada no período vespertino, com taxas superiores a $70 \%$ (Figura 8). Essa redução expressiva registrada nesse período pode ser atribuída ao manejo da cultura, uma vez que as pulverizações são feitas, geralmente, após as $15 \mathrm{~h}$. Assim, a aplicação de agroquímicos interferiu não só na diversidade de visitantes, como também na freqüência da visitação. Esses dados concordam com os de Singh (1989) e Jyothi (1994), indicando que a aplicação de agroquímicos afeta a atividade dos polinizadores de mangueiras e, conseqüentemente, a produção de frutos. Assim, no manejo da cultura, deve ser evitada a aplicação de defensivos no pico da floração e, se necessário, que os mesmos sejam aplicados no final da tarde, quando há menor freqüência de visitação, ou à noite.

TABELA 1 - Número de flores masculinas e hermafroditas em relação ao posicionamento na panícula, da variedade Tommy Atkins, em cultivo convencional e orgânico. Petrolina-PE.

\begin{tabular}{|c|c|c|c|c|c|c|c|c|c|c|}
\hline \multirow{3}{*}{$\begin{array}{c}\text { Posição } \\
\text { na panícula }\end{array}$} & \multicolumn{4}{|c|}{ Masculinas } & \multicolumn{4}{|c|}{ Hermafroditas } & \multicolumn{2}{|c|}{ Total } \\
\hline & \multicolumn{2}{|c|}{ Conv. } & \multicolumn{2}{|c|}{ Org. } & \multicolumn{2}{|c|}{ Conv. } & \multicolumn{2}{|c|}{ Org. } & \multirow{2}{*}{$\begin{array}{c}\text { Conv. } \\
\text { No. } \\
\end{array}$} & \multirow{2}{*}{$\begin{array}{l}\text { Org. } \\
\text { No. }\end{array}$} \\
\hline & No. & $\%$ & No. & $\%$ & No. & $\%$ & No. & $\%$ & & \\
\hline Base & 438 & 60 & 241 & 50 & 144 & 52 & 76 & 35 & 582 & 317 \\
\hline Meio & 206 & 28 & 201 & 42 & 99 & 36 & 109 & 51 & 305 & 310 \\
\hline Ápice & 89 & 12 & 36 & 08 & 33 & 12 & 30 & 14 & 122 & 88 \\
\hline Total & 733 & 100 & 408 & 100 & 276 & 100 & 215 & 100 & 1009 & 693 \\
\hline$\%$ & 73 & & 69 & & 27 & & 31 & & & \\
\hline
\end{tabular}

TABELA 2- Visitantes florais de Mangifera indica L. var. Tommy Atkins, em cultivo convencional e orgânico, com seus respectivos números de visitas, porcentagem, classe de freqüência, recurso floral utilizado e resultado da visita. Classe de Freqüência: $\mathrm{A}=$ Abundante (mais de 30\%); $\mathrm{F}=$ Freqüente (entre 10 e 30\%), e $\mathrm{R}=$ Raro (menos de 10\%). Petrolina-PE.

\begin{tabular}{|c|c|c|c|c|c|c|c|c|}
\hline \multirow[b]{2}{*}{ Visitantes Florais } & \multicolumn{3}{|c|}{ Cultivo Convencional } & \multicolumn{3}{|c|}{ Cultivo Orgânico } & \multirow{2}{*}{$\begin{array}{c}\text { Recurso } \\
\text { floral }\end{array}$} & \multirow{2}{*}{$\begin{array}{c}\text { Resultado } \\
\text { da } \\
\text { visita* }\end{array}$} \\
\hline & $\begin{array}{c}\text { No. } \\
\text { de visitas }\end{array}$ & $\%$ & Freq. & $\begin{array}{l}N^{\circ} \text {. de } \\
\text { visitas }\end{array}$ & $\%$ & Freq. & & \\
\hline \multicolumn{9}{|l|}{ Diptera } \\
\hline Belvosia bicincta & 151 & 17,66 & $\mathrm{~F}$ & 02 & 0,12 & $\mathrm{R}$ & $\mathrm{N}$ & Po \\
\hline Palpada vinetorum & 77 & 9,01 & $\mathrm{R}$ & 51 & 3,17 & $\mathrm{R}$ & $\mathrm{N}$ & Po \\
\hline Ornidia obesa & 38 & 4,44 & $\mathrm{R}$ & 16 & 0,96 & $\mathrm{R}$ & $\mathrm{N}$ & Po \\
\hline Musca domestica & 26 & 3,04 & $\mathrm{R}$ & 165 & 10,27 & $\mathrm{~F}$ & $\mathrm{~N}$ & Po \\
\hline Tachinidae sp1 & 20 & 2,34 & $\mathrm{R}$ & 4 & 0,24 & $\mathrm{R}$ & $\mathrm{N}$ & $\mathrm{Pi}$ \\
\hline Tachinidae sp2 & 14 & 1,64 & $\mathrm{R}$ & -- & -- & -- & $\mathrm{N}$ & $\mathrm{Pi}$ \\
\hline Diptero sp1 & 09 & 1,05 & $\mathrm{R}$ & -- & -- & -- & $\mathrm{N}$ & $\mathrm{Pi}$ \\
\hline Diptero sp2 & 14 & 1,64 & $\mathrm{R}$ & 03 & 0,18 & $\mathrm{R}$ & $\mathrm{N}$ & $\mathrm{Pi}$ \\
\hline \multicolumn{9}{|l|}{ Hymenoptera } \\
\hline Apis mellifera & 389 & 45,62 & A & 1097 & 68,31 & A & $\mathrm{N} / \mathrm{P}$ & Po \\
\hline Trigona spinipes & 39 & 4,56 & $\mathrm{R}$ & 02 & 0,12 & $\mathrm{R}$ & $\mathrm{N}$ & $\mathrm{Pi}$ \\
\hline Brachygastra $\mathrm{sp}$ & 42 & 4,91 & $\mathrm{R}$ & 54 & 3,40 & $\mathrm{R}$ & $\mathrm{N}$ & Po \\
\hline Polistes sp. & -- & -- & -- & 83 & 5,17 & $\mathrm{R}$ & $\mathrm{N}$ & $\mathrm{Pi}$ \\
\hline Camponotus sp. & & & & 27 & 1,68 & $\mathrm{R}$ & $\mathrm{N}$ & $\mathrm{Pi}$ \\
\hline Vespidae sp 1 & 02 & 0,23 & $\mathrm{R}$ & 74 & 4,60 & $\mathrm{R}$ & $\mathrm{N}$ & Po \\
\hline Vespidae sp2 & 07 & 0,82 & $\mathrm{R}$ & 13 & 0,8 & $\mathrm{R}$ & $\mathrm{N}$ & $\mathrm{Pi}$ \\
\hline Vespidae sp3 & 01 & 0,12 & $\mathrm{R}$ & -- & -- & -- & $\mathrm{N}$ & $\mathrm{Pi}$ \\
\hline Vespidae sp4 & -- & -- & -- & 03 & 0,19 & $\mathrm{R}$ & $\mathrm{N}$ & $\mathrm{Pi}$ \\
\hline \multicolumn{9}{|l|}{ Lepidoptera } \\
\hline Urbanus sp. & 02 & 0,23 & $\mathrm{R}$ & -- & -- & -- & $\mathrm{N}$ & $\mathrm{Pi}$ \\
\hline Lepdoptero sp 1 & 23 & 2,69 & $\mathrm{R}$ & -- & -- & -- & $\mathrm{N}$ & $\mathrm{Pi}$ \\
\hline Lepdoptero sp2 & -- & -- & -- & 13 & 0,8 & $\mathrm{R}$ & $\mathrm{N}$ & $\mathrm{Pi}$ \\
\hline TOTAL & 854 & $\mathbf{1 0 0}$ & & 1607 & 100 & & & \\
\hline
\end{tabular}

* $\mathrm{Po}=$ polinizador; $\mathrm{Pi}=$ pilhador 


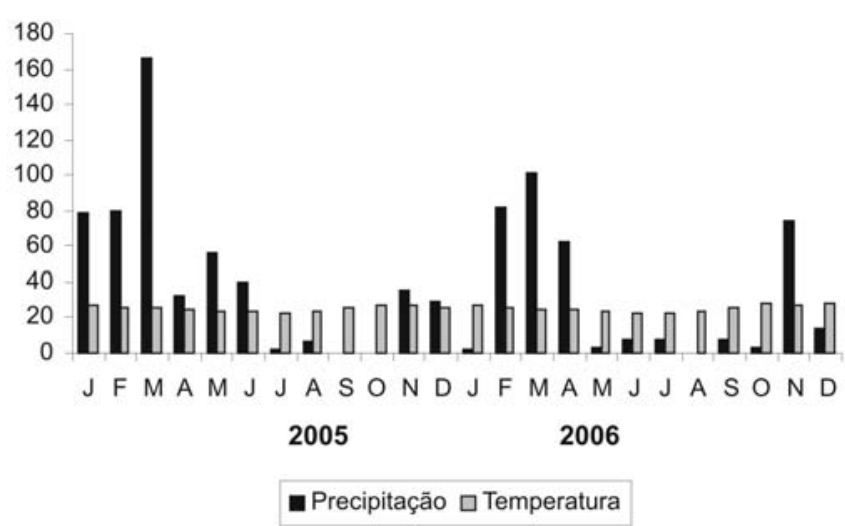

FIGURA 1- Dados médios da Estação Meteorológica da Embrapa Semi-Árido, localizada no Projeto Bebedouro, em Petrolina $\left(09^{\circ} 09^{\prime \prime S ~} 40^{\circ} 22^{\prime \prime W}\right)$, Pernambuco, no período de janeiro de 2005 a novembro de 2006.

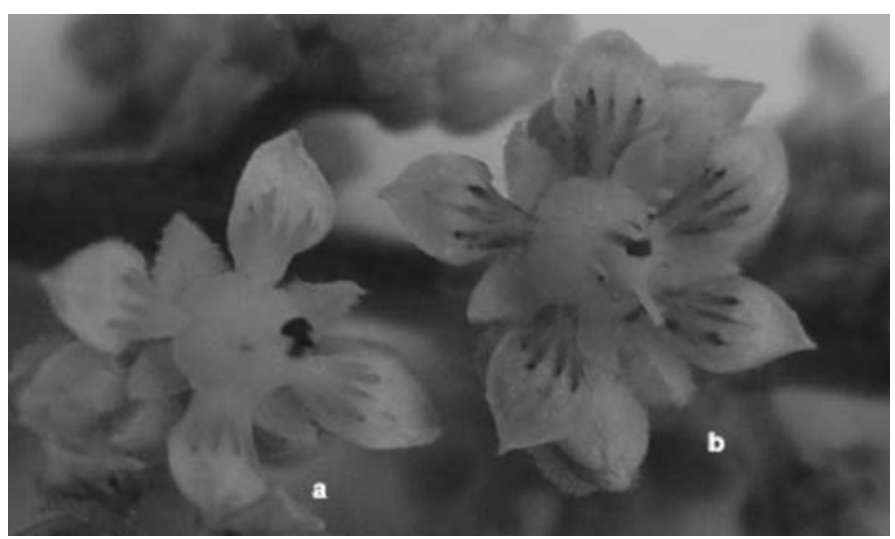

FIGURA 2 - Flores da mangueira. a) em antese. Notar coloração da antera, do filete e dos guias de néctar; b) 24 horas após a antese. Notar alteração de cor das pétalas, dos guias de néctar, dos filetes e das anteras.

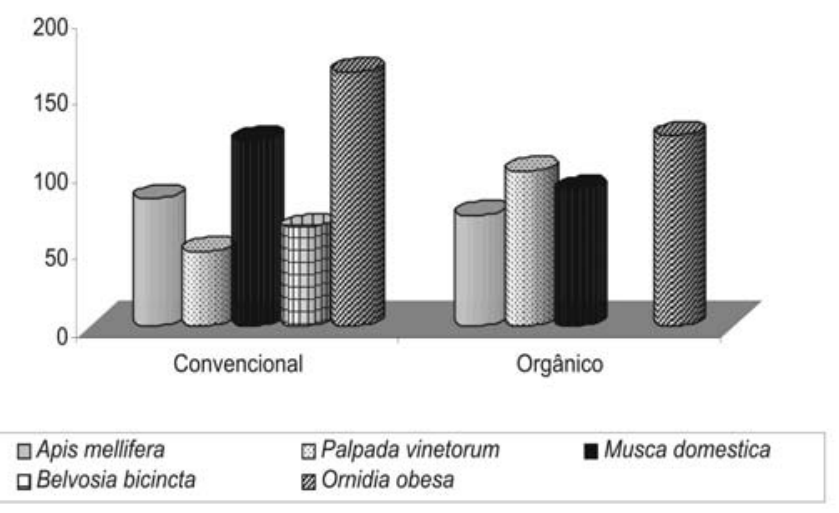

FIGURA 3 -Tempo médio de permanência dos visitantes florais nas panículas da mangueira var. Tommy Atkins, em cultivo convencional e orgânico. Petrolina-PE.

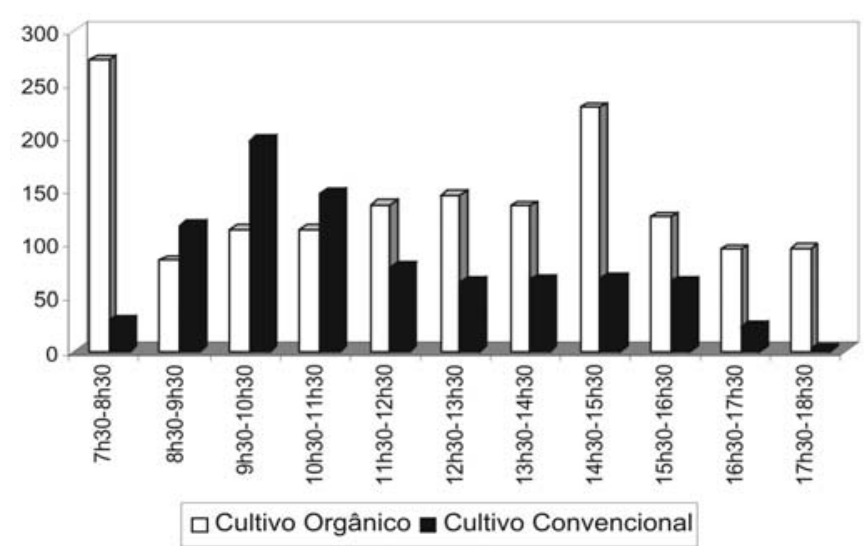

FIGURA 4 - Número total de visitas por intervalo de tempo em panículas da mangueira var. Tommy Atkins, em durante os anos de 2005 e 2006. Petrolina-PE.
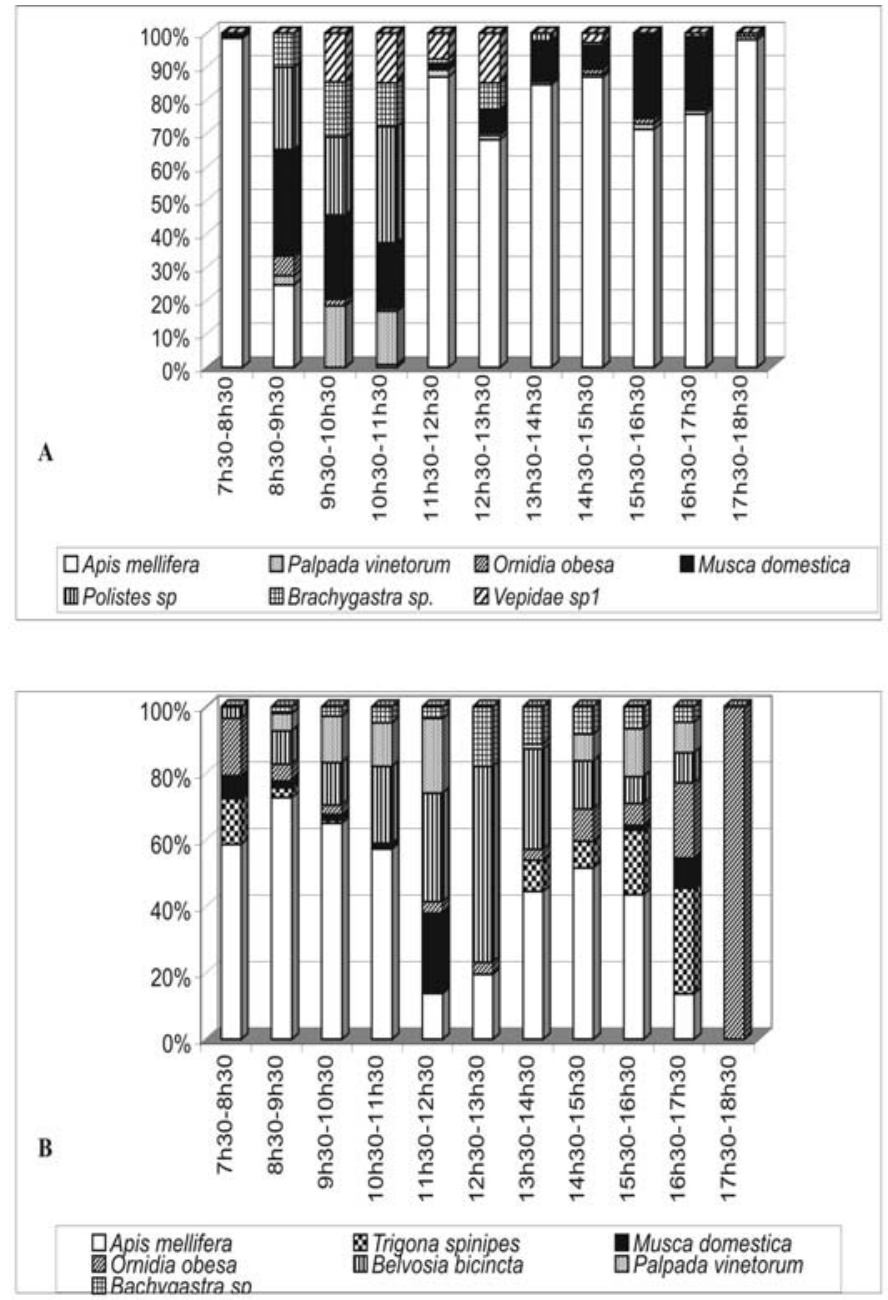

FIGURA 5- Porcentagem de visitas dos insetos às panículas da mangueira var. Tommy Atkins, em diferentes horários, em cultivo orgânico (A) e convencional (B), em Petrolina-PE. 


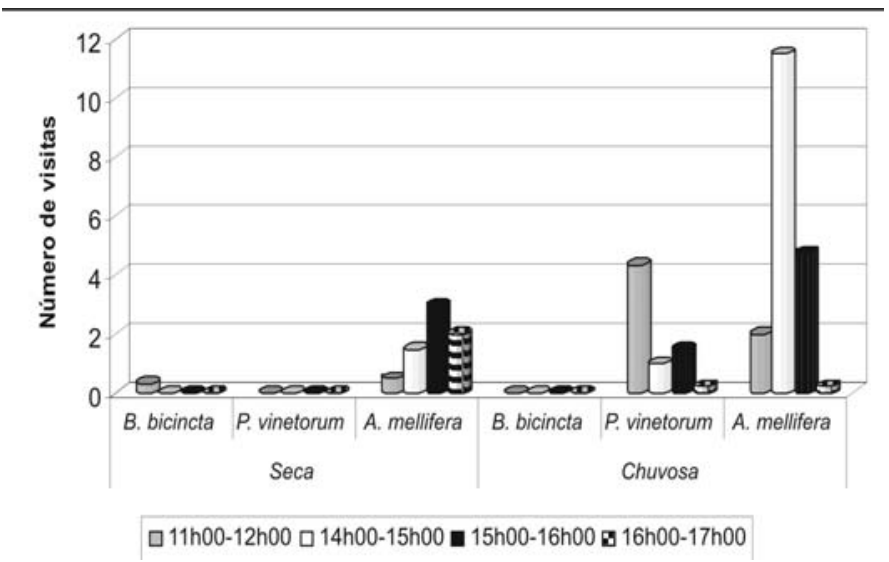

FIGURA 6 - Número médio de visitas dos principais visitantes da Mangifera indica var. Tommy Atkins, em cultivo convencional, durante os períodos seco e chuvoso, nos anos de 2005/2006, em Petrolina-PE.

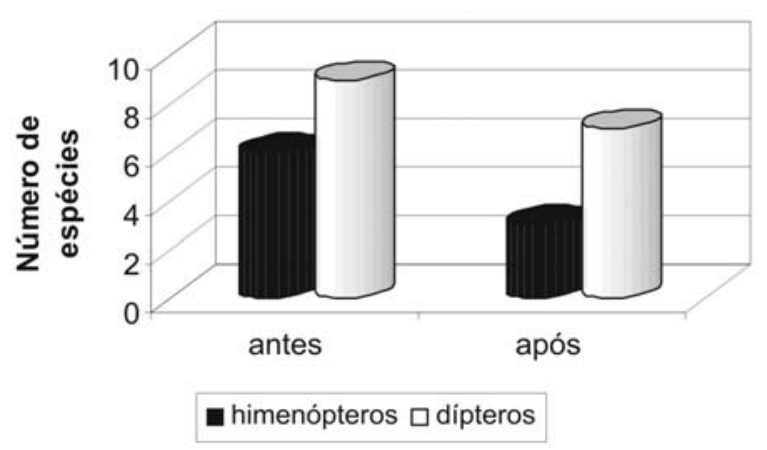

FIGURA 7 - Comparação do número total de visitas, antes e após a pulverização, em cultivo convencional de mangueira da var. Tommy Atkins, em PetrolinaPE.

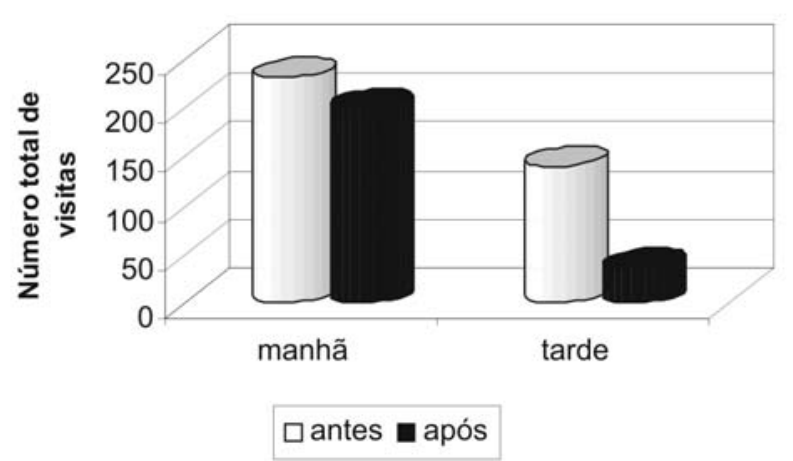

FIGURA 8 - Comparação do número total de visitas registrado para o período da manhã e da tarde, antes e após a pulverização, em cultivo convencional de mangueira da var. Tommy Atkins, em Petrolina-PE.

\section{CONCLUSÕES}

1-A diversidade de visitantes e o número de visitas foram maiores em cultivo orgânico.

2-A aplicação de agroquímicos reduziu a freqüência e a diversidade dos principais polinizadores e, portanto, deve ser evitada no pico da floração e em horários de alta visitação.

3-Apis mellifera, devido ao seu comportamento de coleta, freqüência e ativo deslocamento nas inflorescências, foi considerada como o polinizador mais eficiente da cultura da mangueira na região do Vale Submédio do São Francisco.

4-O design e o entorno da cultura são fatores importante para garantir a diversidade e a manutenção dos visitantes florais.

\section{AGRADECIMENTOS}

Ao PROBIO/MMA/GEF, pelo apoio financeiro durante o desenvolvimento do projeto "Diagnóstico de polinizadores no Vale do São Francisco"; ao CNPq, pela concessão das bolsas de Apoio Técnico; à Fazenda Frutex, pela disponibilização da área experimental; ao Engo. Agrônomo e Apicultor Laércio Alves Puçá Júnior, pelas informações concedidas.

\section{REFERÊNCIAS}

ARRUDA, V. L.V.; SAZIMA, M. Flores visitadas por sirfídeos (Diptera: Syrphidae) em mata mesófila de Campinas, SP. Revista Brasileira de Botânica, São Paulo, v.19, p. 109-117, 1996.

CRUDEN, R. W. Pollen-ovule ratios: A conservative indicator of breeding systems in flowering plants. Evolution, Lawrence, v. 31, p. 32-46, 1977.

DAFNI, A. Pollination ecology: a practical approach. Oxford: Oxford University, 1992.250p.

DAG, A.; DEGANI, C.; GAZIT, S. In-hive pollen transfer in mango. Acta Horticulturae, Wageningem, n. 561, p.61-65, 2001.

DAG, A.; GAZIT, S. Mango pollinators in Israel. Journal of Applied Horticulture, Lucknow, v. 2 n. 1, p.39-43, 2000.

D'AVILA, M.; MARCHINE, L. C. Polinização realizada por abelhas em culturas de importância econômica no Brasil. Boletim Indústria Animal, Nova Odessa, v. 62, n.1, p.79-90, 2005.

FRASER, S. American fruits, their propagation, cultivation, harvesting and distribution. New York: Orange-Judd Publishing, 1927.

KEARNS, C.A; INOUYE, D.W. Techniques for pollination biologists. Colorado: The University Press of Colorado, 1993. p.559. 
INOUYE, D.W. The terminology of floral larceny. Ecology, New York, v. 61, p.1251-1253, 1980.

JIRON, L. F.; HEDSTROM, I. Pollination ecology of mango (Mangifera indica L.) (Anacardiaceae) in the Neotropical Region. Revista Turrialba, Turrialba, v. 35, n. 3, p. 269-277, 1985.

JYOTHI, J. V. A. Visitation frrequncy and abundance of Apis cerana indica F. on mango (Mangifera indica L.) at Bangalore, India. Indian Bee Journal, Nainital, v. 56, n. 1-2, p. 35-36, 1994.

KIILL, L. H. P.; SIQUEIRA, K. M. M. (Coord.) Diagnóstico de polinizadores no Vale do São Francisco: estratégias de manejo de polinizadores de fruteiras no Sub-Médio do Vale do São Francisco. Petrolina: Embrapa Semi-Árido; PROBIO, 2006. CDROM.

MACHADO, I. C. S.; LOIOLA, M. I. Fly pollination and pollinator sharing in two synchronopatric species: Cordia multispicata (Boraginaceae) and Borreria alata (Rubiaceae). Revista Brasileira de Botânica, São Paulo, v. 23, n.3, p. 305-311, 2000.

MCGREGOR, S. E. Insect pollination of cultivated crop plants, Washington: Agricultural Research Service United States Dept. of Agriculture, 1976.411p.

MORALES, M.N.; KÖHLER, A. Espécies de Syrphidae (Diptera) visitantes das flores de Eryngium horridum (Apiaceae) no Vale do Rio Pardo, RS, Brasil. Iheringia, Ser. Zool., Porto Alegre, v. 96, n. 1, p.41-46, 2006.
OCHSE, J. J.; SOULE, M. J.; DIGKRNAN. M. J.; WELTBARG, C. Tropical and subtropical agriculture. New York: Mcmillan, 1961. 1446p.

RADFORD, A. E.; DICKISON, W.C.; MASSEY, J. R.; BELL, C. R. Vascular plant systematics. New York: Harper and Row, 1974.

RAGHAVA KURUP, C. G. (Ed.) The mango: a handbook. New Delhi: India Council Agriculture Reseaech, 1967.210p.

SINGH, R. N.; MAJUMDAR, P. K.; SHARMA, D. K. Self incompatibility in mango (Mangifera indica L.) Var. Dashehari. Current Science, Bangalore, v. 31, n. 5, p. 209, 1962.

SINGH, G. Insect pollinators of mango and their role in fruit setting. Acta Horticulturae, Wageningen, v. 231, p.629-632, 1989.

SINGH, G. Pollination, Pollinators and fruit setting in mango. Acta Horticulturae, Wageningen, v.1, n. 455, p. 116-123, 1997.

STURROCK, T. T. Notes on the mango. Sturast, Fla: Daily News, 1944. 122p.

VIANA, B. F. (Coord.) Plano de manejo para polinizadores: A mangueira, e seus potenciais polinizadores no Vale Médio São Francisco, Juazeiro, Bahia. Salvador: PROBIO. (Manual Técnico). Disponível em: $<$ http://www.labea.ufba.br $>$. Acesso em: 15 fev 2006.

YOUNG, T. W. Investigations of the unfruitfulness of Haden mango in Flórida. Proceedings of the Florida. State Horticultura Society, Winter Haven, v.55, p. 106-110, 1942. 